\title{
DETERMINAÇÃO DOS TRAÇOS FUNCIONAIS DA AVIFAUNA DA ÁREA DE PROTEÇÃO AMBIENTAL DO PRATIGI, BAHIA.
}

\section{Fernando Henrique Santos Ferreira; Caio Graco Machado.}

Bolsista PROBIC/CNPq, Graduando em Licenciatura em Ciências Biológicas, Universidade Estadual de Feira de Santana, e-mail: nando_hsf@hotmail.com Caio Graco Machado. Departamento DCBio, Universidade Estadual de Feira de Santana, e-mail: gracom@uol.com.br

Participante do projeto Aspectos ecológicos da avifauna da APA Pratigi, Departamento DCBio, Universidade Estadual de Feira de Santana,

PALAVRAS-CHAVE: Ecologia de Comunidades, Ecologia Funcional, Mata Atlântica

\section{INTRODUÇÃO}

A Mata Atlântica é reconhecida como um dos conjuntos de ecossistemas mais biodiversos (ROCHA, 2007). Estudos realizados em fragmentos de Mata Atlântica do sul da Bahia evidenciaram que a região pode ser considerada um hotspot de biodiversidade do bioma (MARTINI et al., 2007; THOMAS et al., 2009). Ainda nesta região, chama atenção o grau de endemismo de algumas áreas (THOMAS et al., 2009); com relação à avifauna, o bioma abriga cerca de 620 espécies de aves - sendo 160 endêmicas (ROCHA, 2007), além de apresentar muitas espécies endêmicas de vegetais, insetos, anfíbios e mamíferos. (MORI et al. 1983). No entanto, muitos taxa se encontram ameaçados de extinção, uma vez que este bioma é considerado um dos mais fragmentados e ameaçados do globo (BIBBY et al. 1992).

A diversidade funcional é um componente da biodiversidade que busca medir a extensão das diferenças funcionais entre as espécies, com base na diversidade de suas características morfológicas, fisiológicas e ecológicas (PETCHEY \& GASTON,2006). As características funcionais em uma comunidade representam as interações que interferem na abundância e dinâmica populacional dos organismos, nas estruturas trófica e ambiental (NAEEM \& WRIGHT 2003). Desta forma, em ecologia, as palavras função, funcional e funcionamento se referem ao modo pelo qual o ecossistema opera, sem condicionar um propósito ou um objetivo, o que seria inconsistente aos preceitos evolutivos. Uma definição para diversidade funcional é 'o valor da variação das espécies e de suas características que influenciam o funcionamento das comunidades' (TILMAN 2001).

No bioma Mata Atlântica, são poucos os estudos que avaliaram padrões e processos de estruturação das comunidades de aves, porém alguns estudos (CASAS et al., 2016; MENDONÇA DE LIMAET et al., 2016) concluíram que as características da vegetação influenciam a diversidade taxonômica e das guildas tróficas, sendo que as comunidades de aves florestais a presentam estruturação vertical, ou seja, espécies associadas a diferentes estratos e substratos da mata.

O estudo sobre a diversidade funcional é um importante recurso alternativo para analisar as mudanças nas funções e serviços do ecossistema provido pelas aves da Mata Atlântica, tendo em vista que, por meio dos traços funcionais, as aves têm importância direta sobre os serviços ecossistêmicos e, desta forma, este grupo contribui em uma série de funções, como no controle de pragas, na ciclagem de nutrientes e na dispersão de sementes (SEKERCIOGLU, et al 2012).

\section{MATERIAL E MÉTODOS.}

O presente estudo foi desenvolvido a partir dos inventariados das comunidades de aves em três áreas, denominadas Ecopólos, da Área de Proteção Ambiental (APA) do Pratigi, uma unidade de conservação situada na região Baixo Sul da Bahia, no domínio 
Mata Atlântica, que abrange os municípios Ibirapitanga, Igrapiúna, Ituberá, Nilo Peçanha e Piraí do Norte.

As três áreas da APA do Pratigi são: Ecopolo I, com sede no município de Ibirapitanga, Ecopolo II, com sede no município de Igrapiúna e Ecopolo III, no município de Ituberá. O presente estudo foi desenvolvido em duas etapas:

1) A compilação das listas de espécies de aves dos Ecopolos I, II e III: as espécies de aves que compõe cada uma das três áreas da APA do Pratigi têm sido inventariadas pela equipe do Laboratório de Ornitologia (Ornito/UEFS) desde 2012 (Colocar aqui as referências das dissertações de Fernando, Maurício, etc)

2) A atribuição dos traços funcionais para cada espécie: a partir da lista de espécies que compõe a comunidade de aves de cada um dos três ecopolos da APA do Pratigi, foram atribuídas, para cada espécie, suas características (traços) funcionais, através de dados em literatura especializada (SICK, 1997; FLORES, 2014; SETUBAL, 2015; ROCHA, 2017). Foram considerados um traço funcional contínuo (massa corpórea média, em gramas) e 25 traços funcionais categóricos, relacionados com o forrageamento. Foram considerados os seguintes traços funcionais categóricos: a) itens alimentares: invertebrados; frutos; sementes e grãos; néctar; flores, frutos e tubérculos; vertebrados; b) sítios de forrageio: dossel; sub-bosque; vegetação baixa/rasteira; solo; água; lama; ar); c) método de forrageio: perseguir; respigar; investir-pousar; bicar; pastejar; explorar; respigar d) período de forrageio: diurno; noturno; d) participação em bando misto: sim; não.

\section{RESULTADOS E DISCUSSÃO.}

No total foram listadas e analisadas 309 espécies (180 ocorrentes no Ecopolo I, 250 no Ecopolo II e 115 no Ecopolo III). Os grupos tróficos predominantes são os de insetívoros e frugivoros (Figura 1). Em uma comunidade, os insetívoros têm um importante papel no controle das populações de insetos e, por consequência, na conservação da vegetação local, pois o aumento das populações de insetos e herbívoros impactariam fortemente a comunidade vegetal. Muitas espécies de aves frutívoras são dispersoras de semente, e, por isso, são consideradas essenciais para a dinâmica e estrutura das comunidades vegetais (PIZO, 2001).

Os locais de maior forrageamento foram o sub-bosque (40\%), o dossel e a vegetação baixa/rasteira (Figura 2). A vegetação subarbustiva é um sistema sombreado pela densa vegetação superior, servem de abrigo para muitas aves, além de possuírem uma grande diversidade de plantas e animais; é no subbosque que se encontram a maioria das espécies ornitocóricas, cujos frutos são recurso para aves frugívoras (PIZ0 2001).

Quanto aos métodos de forrageio, o tipo respigar (recolher) utilizado por grande parte das aves, é presumivelmente uma manobra de menor custo energético (REMSEN, 1985) (Figura 3). Cerca de $45 \%$ das espécies de aves associam-se aos bandos mistos (Figura 4), o que é esperado em comunidades tropicais, uma vez que em bandos há diminuição do risco de predação e, ainda, maximização do forrageio (MACHADO 1999). Como se espera na Classe Aves, as espécies diurnas predominaram (Figura 5); as noturnas restringem-se sobretudo às corujas e bacuraus (famílias Stringidae e Caprimulgidae). 


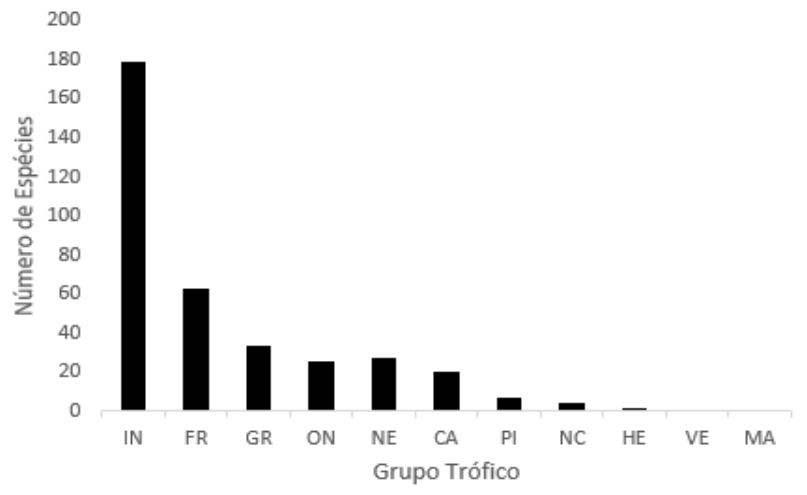

Figura 1. Grupos tróficos da avifauna da Área de Proteção Ambiental do Pratigi, Bahia: IN - insetívoro, FR - frugívoro, ON - onívoro; NE - nectarívoro; CA carnívoro; GR - granívoro, PI - piscitívoro; NC necrófago; HE - herbívoro; MA - malacófago; VE vermívoria

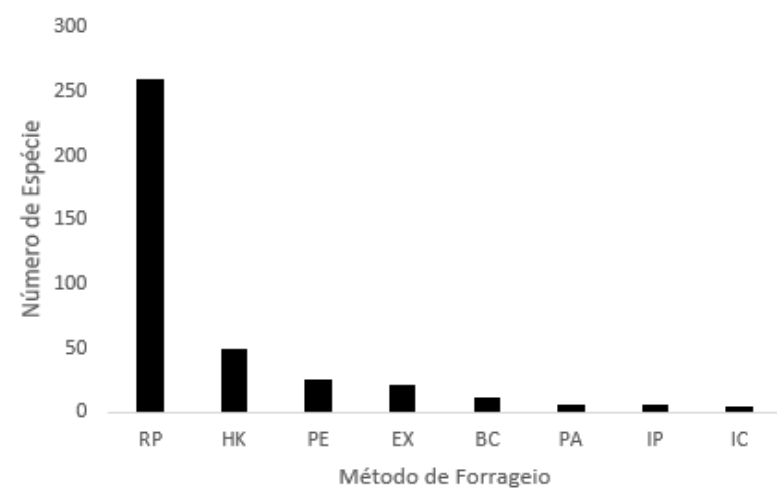

Figura 3. Método de forrageio da avifauna da Área de Proteção Ambiental do Pratigi, Bahia. RP - respigar (recolher); HK - Hawking (capturar alimento durante o voo); PE - perseguir; EX - explorar; BC - bicar; PA pastejar; IP - investir e pousar; IC - investir em carcaças

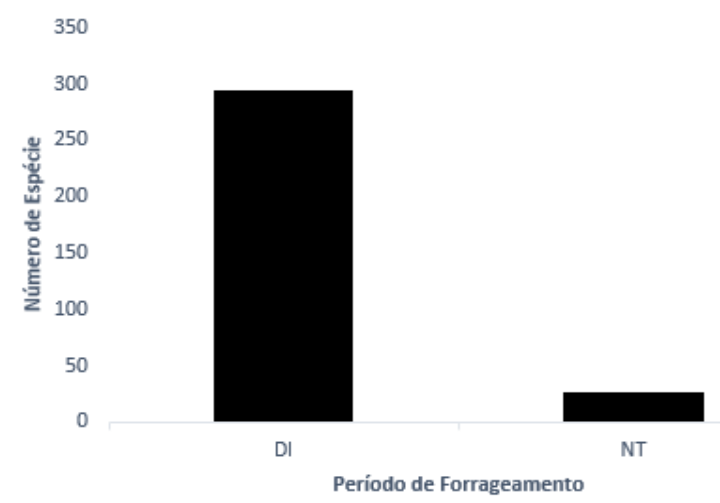

Figura 5. Período de forrageio da avifauna da Área de Proteção Ambiental do Pratigi, Bahia. DI - diurno; NTnoturno.

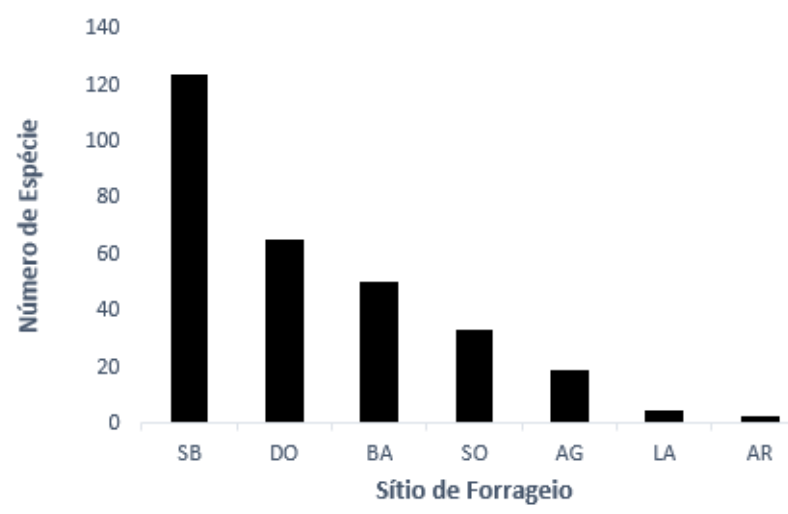

Figura 2. Sítio de forrageio da avifauna da Área de Proteção Ambiental do Pratigi, Bahia. SB - sub-bosque; DO - dossel; BA - vegetação baixa/rasteira; SO - solo; AG - água; LA - lama; AR - aéreo

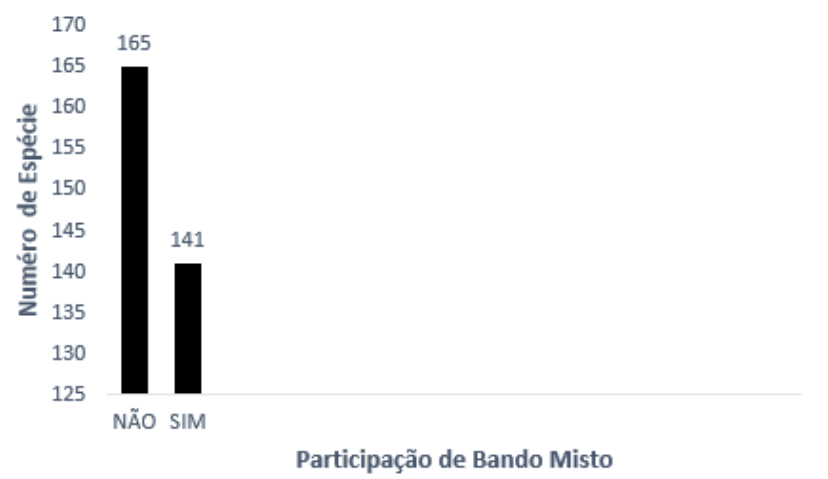

Figura 4. Participação de Bando Misto das espécies de aves Área de Proteção Ambiental do Pratigi, Bahia.

\section{CONSIDERAÇÕES FINAIS.}


Estudos sobre avifauna são muito importantes pois indicam relações intraespecífica e interespecíficas, partição e utilização de recursos, relações de nichos, interações de mesmas espécies em diferentes habitats, entre outros fatores importantes da biologia dos animais. Dessa maneira, por contribuírem para o aprofundamento do conhecimento sobre a composição e aspectos da comunidade de aves da região de aves da APA do Pratigi sob ótica da Ecologia Funcional, e também os dados apresentados, podem subsidiar a identificação de uma área prioritária para a conservação da diversidade biológica no estado da Bahia.

\section{REFERÊNCIAS}

BIBBY, C.J.; N.J. COLLAR; M.J. CROSBY; F. HEATH; C. IMBODEN; T.H. JOHNSON; A.J. LONG; A.J. STATTERSFIELD \& S.J. THIRGOOG. Putting biodiversity on the map: priority areas for global conservation. Cambridge, I.C.B.P. p, 235. 1992

CASAS, G., DARSKI, B., FERREIRA, P. M. A., \& MÜLLER, S. C. 2016. Habitatstructure influences the diversity, richness and composition of bird assemblages insuccessional Atlantic rain forests.Tropical Conservation Science, 9, 503-524. 2016.

MACHADO, C. G. 1999. Composição e estrutura de bandos mistos de aves na Mata Atlântica do alto da Serra do Paranapiacaba, SP. Revista Brasileira de Biologia, 59: 75-85

MARTINI, A. M. Z.; FIASCHI, P.; AMORIM, A. M.; PAIXÃO, J. L. A hot-point within a hotspot: a high diversity site in Brazil's atlantic forest. Biodiversity and Conservation, v. 16, n. 11, p. 3111-3128, Oct. 2007.

MENDONÇA LIMA, A., BOSCHILIA, S. M., SILVA, J. B., \& BALDISSERA, R. .Effect of habitat heterogeneity on bird assemblages in a grassland-forest ecotone inBrazil.Revista Acta Ambiental Catarinense, 13, 8-16. 2016

MOREIRA, F. F. Composição e dinâmica de bandos mistos de aves da Mata Atlântica do Baixo Sul da Bahia, Brasil. 2014. 73 f. Dissertação (Mestrado) - Curso de Pós-graduação em Zoologia, Ciências Biológicas, Universidade Estadual de Feira de Santana, Feira de Santana, 2014.

MORI S.A. B.M. BOOM; A.M. CARVALHO \& T.S. SANTOS. Southern Bahian moist forest. Botanical Review, Cambridge, 49 (1): 155-232. 1983.

NAEEM, S., AND J. P. WRIGHT. Disentanglingbiodiversity effects on ecosystem functioning: deriving solutions to a seemingly insurmountable problem. Ecology Letters 6:567-579. http://dx.doi.org/10.1046/j.1461-0248.2003.00471.x. 2003

PETCHEY, O. L., AND K. J. GASTON. Functional diversity: back to basics and looking forward. Ecology Letters 9:741-758. 2006.

PIZO, M. A. A conservação das aves frugívoras. Ornitologia e conservação: da ciência às estratégias. Tubarão: Ed Unisul, p. 49-59, 2001.

ROCHA, L. Meio Ambiente no Baixo Sul. In: FISCHER, F. Baixo Sul da Bahia: uma proposta de desenvolvimento territorial. Salvador: CIAGS/UFBA, pág. 81-85. 2007.

ROCHA, J. S. Diversidade funcional de aves em fragmentos florestais e plantações de cacau de uma região de alta importância biológica da Mata Atlântica, Brasil. 2017. 87 f. Dissertação (Mestrado) - Curso de Programa de Pós-graduação em Ecologia e Conservação da Biodiversidade, Universidade Estadual de Santa Cruz, Ilhéus, 2017.

REMSEN Jr, J. V. Community organization and ecology of birds of high elevation humid forest of the Bolivian Andes. Ornithological Monographs, Albuquerque, n. 36, p. 733-756, 1985

SETUBAL, M. J. COMPOSIÇÃO ESPECÍFICA E ESTRUTURA TRÓFICA DA AVIFAUNA EM DUAS ÁREAS DE MATA ATLÂNTICA NO BAIXO SUL DA BAHIA. 2015. $60 \mathrm{f}$. Dissertação (Mestrado) - Curso de Pós-graduação em Zoologia, Ciências Biológicas, Universidade Estadual de Feira de Santana, Feira de Santana, 2015

THOMAS, W. W.; JARDIM, J. G; FIASCHI, P.; MARIANO NETO, E.; AMORIM, A. M. et al. Composição florística e estrutura do componente arbóreo de uma área transicional de Floresta Atlântica no sul da Bahia, Brasil. Rev. Bras. Bot., v. 32, n. 1, p. 65-78, mar. 2009.

TILMAN, D. Functional diversity. Encyclopedia of diversity. p, 109-121. 2001 